\title{
The weakening effect of soluble epoxide hydrolase inhibitor AUDA on febrile response to lipopolysaccharide and turpentine in rat
}

\author{
Jakub Piotrowski ${ }^{1}$ (i) - Tomasz Jęrrzejewski ${ }^{1}$ - Malgorzata Pawlikowska ${ }^{1}$ • \\ Agata Joanna Pacula ${ }^{2}$. Jacek Ścianowski ${ }^{2} \cdot$ Wieslaw Kozak $^{1}$
}

Received: 22 December 2016 / Accepted: 18 July 2017 /Published online: 24 July 2017

(C) The Author(s) 2017. This article is an open access publication

\begin{abstract}
A still growing body of evidence suggests the importance of epoxyeicosatrienoic acids (EETs) in the regulation of inflammatory response; therefore, drugs that stabilize their levels by targeting the soluble epoxide hydrolase (sEH), an enzyme responsible for their metabolism, are currently under investigation. The effect of sEH inhibitors on molecular components of fever mechanism, i.e., on synthesis of proinflammatory cytokines or prostaglandins, has been repeatedly proven; however, the hypothesis that $\mathrm{SEH}$ inhibitors affect febrile response has never been tested. The aim of this study was to examine if sEH inhibition affects core body temperature $(\mathrm{Tb})$ as well as $\mathrm{Tb}$ changes during febrile response to infectious (lipopolysaccharide; LPS) or non-infectious (turpentine; TRP) stimuli. Male Wistar rats were implanted intra-abdominally with miniature biotelemeters to monitor Tb. A potent sEH inhibitor 12-(3-adamantan-1-yl-ureido)-dodecanoic acid (AUDA) was suspended in olive oil and administrated into animals in the intraperitoneal (i.p.) dose of $15 \mathrm{mg}$ / $\mathrm{kg}$, which, as we showed, has no significant influence on normal $\mathrm{Tb}$. We have found that AUDA injected $3 \mathrm{~h}$ after LPS $(50 \mu \mathrm{g} / \mathrm{kg}$ i.p.) significantly weakened febrile rise of $\mathrm{Tb}$. Moreover, injection of sEH inhibitor $7 \mathrm{~h}$ after turpentine (administrated subcutaneously in a dose of $100 \mu \mathrm{L} /$ rat) markedly reduced the peak period of aseptic fever. Obtained results provide first experimental evidence that $\mathrm{sEH}$ inhibitors
\end{abstract}

Jakub Piotrowski

piotrowski_jak@umk.pl

1 Department of Immunology, Faculty of Biology and Environment Protection, Nicolaus Copernicus University, 1 Lwowska Street, 87-100 Torun, Poland

2 Department of Organic Chemistry, Faculty of Chemistry, Nicolaus Copernicus University, 7 Gagarina Street, 87-100 Torun, Poland possess anti-pyretic properties. Therefore, medicines targeting sEH enzymatic activity should be considered as a complement to the arsenal of topical medications used to treat fever especially in clinical situations when non-steroidal anti-inflammatory drugs are ineffective.

Keywords Inflammation $\cdot$ Fever $\cdot$ EETs $\cdot$ Anti-pyretic $\cdot$ Soluble epoxide hydrolase $\cdot$ Biotelemetry

\section{Introduction}

Fever, also known as pyrexia, is a regulated rise in body temperature $(\mathrm{Tb})$ that is most frequently associated with infection, inflammation, and trauma. Experimental data strongly suggest important role of cytokines, especially interleukin (IL)- $1 \beta$ and IL- 6 and tumor necrosis factor- $\alpha$ (TNF- $\alpha$ ), as endogenous mediators of this physiological response $[4,16]$. Pyrogenic cytokines are involved in stimulation of acute phase proteins, activation of hypothalamic-pituitary-adrenal (HPA) axis, and initiation of the arachidonic acid (AA) liberation from membrane phospholipids [15]. Free AA is a precursor for eicosanoids - signaling molecules that exert complex control over many bodily systems [3]. The cyclooxygenase (COX) pathway of AA metabolism, which can be inhibited by nonsteroidal anti-inflammatory drugs (NSAIDs) or recently developed COXIBs (selective inhibitors of inducible form of cyclooxygenase, $\mathrm{COX}-2$ ), produces prostaglandin $\mathrm{E}_{2}$ $\left(\mathrm{PGE}_{2}\right)$ - another important downstream mediator of fever and inflammation [2]. In contrast, cytochrome P-450 monooxygenase (epoxygenase)-derived metabolites of AA, namely epoxyeicosatrienoic acids (EETs), possess antiinflammatory and anti-pyretic properties. Kozak and coworkers proved that various isomers of EETs administered into the lateral ventricle reduce lipopolysaccharide (LPS)- 
induced fever in rats [17]. However, EETs have a short halflife limiting their therapeutic application, ranging from seconds to minutes [10], and are rapidly conversed to far less biologically active or inactive dihydroxyeicosatrienoic acids (DHETs) by soluble epoxide hydrolase (sEH) [6]. Thus, inhibitors of the sEH (sEHi) that stabilize and increase the EET levels are increasingly studied in rodent models of various diseases [as reviewed in 21]. Moreover, sEH inhibitors have been shown to downregulate the expression of COX-2 protein and synergize well with NSAIDs towards the reduction of inflammation [26] as well as LPS-induced plasma levels of pro-inflammatory cytokines [27]. Thus, given the evidence that inhibition of sEH activity affects molecular components of fever mechanism: cytokines, prostaglandins, and EET bioavailability, the present study aimed to determine the effect of a potent sEH inhibitor 12-(3-adamantan-1-yl-ureido)-dodecanoic acid (AUDA) on Tb changes in a course of febrile response to infectious and non-infectious stimuli in rat. Inhibition of sEH enzyme constitutes innovative approach in treating fever; thereby, drugs targeting this enzyme might complete the arsenal of available medicines, especially in clinical situations where oral anti-pyretics are only marginally effective, for example in lowering elevated $\mathrm{Tb}$ occurring after stroke [40].

\section{Materials and methods}

\section{Experimental animals}

Male Wistar Crl:WI(Han) rats aged 8-12 weeks and weighing from 250 to $300 \mathrm{~g}$ were purchased from the Mossakowski Medical Research Centre Polish Academy of Sciences (Warsaw, Poland) and were acclimatized for 10 days before starting the experiments. Animals were kept individually in a room at constant relative humidity $(60 \pm 5 \%)$ and temperature $\left(24 \pm 1{ }^{\circ} \mathrm{C}\right)$, with a $12: 12$-h light-dark photoperiod, with lights on at 7:00 h. Rodent laboratory food and drinking water were provided ad libitum.

All procedures were approved by the Local Bioethical Committee for Animal Care (permission no. 9/2015).

\section{Temperature measurements}

To monitor the core $\mathrm{Tb}$, all animals were implanted intraabdominally with temperature-sensitive miniature biotelemeters PhysioTels model TA10TA-F40 (Data Sciences International, St. Paul, MN, USA) under sterile condition [for details, see 39]. All surgical procedures were done at least 2 weeks before the start of experiments.

\section{Reagents and injections}

Systemic inflammation was provoked by intraperitoneal (i.p.) injection of bacterial lipopolysaccharide (LPS) while local aseptic necrosis of tissues was induced with turpentine (TRP) administrated subcutaneously (s.c.). It is well established that injections of both agents provoke characteristic, reproducible febrile rise of $\mathrm{Tb}$ in rats [for, e.g., see $23,31,39]$.

LPS derived from Escherichia coli 0111:B4 (SigmaAldrich, St. Louis, MO, USA) was dissolved in pyrogenfree $0.9 \%$ sodium chloride (saline) to obtain the final concentration of $50 \mu \mathrm{g} / \mathrm{mL}$. LPS was injected i.p. in a dose of $50 \mu \mathrm{g} /$ $\mathrm{kg}$ to provoke endotoxin fever. Intraperitoneal injection of saline $(1 \mathrm{~mL} / \mathrm{kg})$ was used as a control.

Aseptic necrosis of tissues was induced with undiluted turpentine oil (Elissa, Warsaw, Poland). Turpentine was injected s.c. into the right hindlimb at a volume of $0.1 \mathrm{~mL} /$ rat.

sEH inhibitor 12-(3-adamantan-1-yl-ureido)-dodecanoic acid (AUDA) was synthetized according to the procedure [13]. Dose of AUDA was suspended in $500 \mu \mathrm{L}$ of olive oil, then sonicated, and vortexed to obtain homogeneous suspension. Suspensions were made individually for each animal freshly before use and injected i.p. in a dose of 5, 15, or $30 \mathrm{mg} / \mathrm{kg}$ according to the experiment. As a control, animals received i.p. injection of olive oil in a volume of $500 \mu \mathrm{L}$.

All rats were restrained and not anesthetized during injections. The animals were weighed before injections to determine the precise doses of LPS and AUDA.

\section{Anti-TNF- $\alpha$ antibody injection}

TNF- $\alpha$ antibodies (rabbit polyclonal IgG anti-rat TNF- $\alpha$; Thermo Scientific, Waltham, MA USA; cat. no. PRTNFAI) were injected i.p. in a dose of $50 \mu \mathrm{g} / \mathrm{rat}$ in a volume of $500 \mu \mathrm{L}$ of phosphate-buffered saline $1 \mathrm{~h}$ prior to the injection of AUDA. Rabbit IgG (Rockland Immunochemicals, Limerick, PA, USA; cat. no. 011-001-297) was used as a control. The dose of TNF- $\alpha$ antibody ( $50 \mu \mathrm{g} /$ rat corresponds to the dose of $200-250 \mu \mathrm{g} / \mathrm{kg}$ ) was selected according to the results of our previous experiments [12].

\section{TNF- $\alpha$ assay}

Blood was collected from anesthetized rats (mixture of ketamine/xylazine) by cardiac puncture into the solution of ethylenediaminetetraacetic acid (EDTA, Sigma-Aldrich, St. Louis, MO, USA). Plasma was separated by a centrifugation (20 min $1000 \times g$ ) within $30 \mathrm{~min}$ of collection and was kept frozen at $-20{ }^{\circ} \mathrm{C}$ until assay. Blood for analyses was collected an hour after LPS injection, at the time of the greatest decrease in $\mathrm{Tb}$ of rats observed with biotelemetry. 
The levels of TNF- $\alpha$ were determined by a standard sandwich ELISA kit from Invitrogen (Camarillo, CA, USA cat. no. $\mathrm{KRC} 3011$; the minimum detectable dose of rat TNF- $\alpha$ is $<4 \mathrm{pg} / \mathrm{mL}$ ) according to the manufacturer's instructions. Colorimetric changes in the assay were detected using the Synergy HT Multi-Mode Microplate Reader (BioTek, Winooski, VT, USA).

\section{Statistics}

Temperature values are reported as means \pm standard error mean (SEM). Five-minute temperature recordings were pooled into 30-min averages for presentation. Mean values \pm SEM of TNF- $\alpha$ concentrations in plasma were calculated for five plasma samples, each from different animal in the experimental group, that were assayed in duplicate. ANOVA with repeated measures followed by a Tukey multiple comparison post hoc test was used to determine the differences in time-dependent patterns of temperature among groups. ANOVA followed by Tukey pairwise comparison was used to test for statistical differences among groups at individual time points as well as TNF- $\alpha$ contents. Differences were considered significant at $p<0.05$.

\section{Results}

\section{Dose-dependent effect of AUDA on Tb in rats}

The effect of AUDA on changes of Tb in male Wistar rats is illustrated in Fig. 1b. Three doses of $\mathrm{sEH}$ inhibitor $(5,15$, and $30 \mathrm{mg} / \mathrm{kg}$ ) were suspended in olive oil and injected i.p. into the separate groups of rats. Injection of olive oil alone (in a volume of $500 \mu \mathrm{L}$ i.p.) did not cause significant $(p>0.05)$ changes in $\mathrm{Tb}$ in rats compared to non-treated animals as can be seen in Fig. 1a. Similarly, AUDA in a dose of $5 \mathrm{mg} / \mathrm{kg}$ as well as $15 \mathrm{mg} / \mathrm{kg}$ had only slender influence on $\mathrm{Tb}$. Mean daytime Tb measured between 9:00 and 19:00 in control (non-treated) animals $\left(37.21 \pm 0.07{ }^{\circ} \mathrm{C}\right.$ ) was comparable $(p>0.05)$ to "olive" $\left(37.22 \pm 0.07{ }^{\circ} \mathrm{C}\right)$ and "AUDA $5 \mathrm{mg} / \mathrm{kg}$ " $\left(37.24 \pm 0.07{ }^{\circ} \mathrm{C}\right)$ as well as to “AUDA $15 \mathrm{mg} / \mathrm{kg} "\left(37.17 \pm 0.06^{\circ} \mathrm{C}\right)$ experimental groups. However, AUDA injected in a dose of $30 \mathrm{mg} / \mathrm{kg}$ visibly affected $\mathrm{Tb}$ of rats. Mean $\mathrm{Tb}$ of animals from the experimental group "AUDA $30 \mathrm{mg} / \mathrm{kg}$ " $\left(37.43 \pm 0.04{ }^{\circ} \mathrm{C}\right)$ was significantly $(p<0.001)$ higher between 8:00 and 13:30 compared to "NT" $\left(37.12 \pm 0.03{ }^{\circ} \mathrm{C}\right)$ and other groups. There were no significant $(p>0.05)$ changes in $\mathrm{Tb}$ between animals treated with AUDA and non-treated rats measured from 14:00 to 19:00.

Considering the obtained results, we decided to use AUDA in a dose of $15 \mathrm{mg} / \mathrm{kg}$ for further experiments as the highest dose that has not influenced the normal $\mathrm{Tb}$ of rats.

\section{AUDA weakened aseptic fever in rats}

To determine the effect of sEH inhibition on aseptic fever, animals were injected with turpentine at time 8:00 and with AUDA or olive oil as a control after $7 \mathrm{~h}$. As can be seen in Fig. 2, injection of turpentine provoke rise in $\mathrm{Tb}$ that started in both experimental groups with latency period lasting for c.a. 5-6 h. Then, temperature had gradually grown reaching highest values at 18:00. In comparison to rats treated intraperitoneally at 15:00 with olive oil, injection of AUDA significantly reduced the peak period of aseptic fever. Mean $\mathrm{Tb}$ of rats injected with oil measured between $16: 00$ and midnight $\left(38.93 \pm 0.05{ }^{\circ} \mathrm{C}\right)$ as well as maximum value of $\mathrm{Tb}$ rise $\left(39.20 \pm 0.09^{\circ} \mathrm{C}\right.$ at $\left.18: 00\right)$ was significantly $(p<0.001)$ higher than in animals treated with AUDA (mean Tb measured for the same time interval was $38.60 \pm 0.06{ }^{\circ} \mathrm{C}$ and maximum of $\mathrm{Tb}$ rise reached $38.89 \pm 0.15{ }^{\circ} \mathrm{C}$ at 18:00, respectively). Then, a 6-hlasting gradual decrease of $\mathrm{Tb}$ towards normal was observed, which did not significantly $(p>0.05)$ differ in both experimental groups.

\section{AUDA weakened endotoxin fever in rats}

As can be seen in Fig. 3, i.p. injection of LPS (in a dose of $50 \mu \mathrm{g} / \mathrm{kg}$ ) induced characteristic biphasic fever in rats that started with latency period lasting $1.5 \mathrm{~h}$. The first peak of $\mathrm{Tb}$ rise was observed $2.5 \mathrm{~h}$, while second $6 \mathrm{~h}$ after LPS injection in both experimental groups. Until the AUDA or olive oil injection, $\mathrm{Tb}$ in both groups did not differ. However, the febrile response was strongly weakened in the animals that received sEH inhibitor $3 \mathrm{~h}$ after LPS compared to rats injected with olive oil as a control. The maximum value of $\mathrm{Tb}$ rise in the "LPS/AUDA" group of rats $\left(38.33 \pm 0.15^{\circ} \mathrm{C}\right)$ as well as mean $\mathrm{Tb}\left(38.03 \pm 0.09{ }^{\circ} \mathrm{C}\right)$ measured between 13:30 and 17:30 was significantly $(p<0.001)$ lower than in the "LPS/ oil" group (with $\mathrm{Tb} \max 38.76 \pm 0.12{ }^{\circ} \mathrm{C}$ ) and mean $\mathrm{Tb}$ $38.47 \pm 0.09{ }^{\circ} \mathrm{C}$ measured for the same time period).

\section{AUDA pre-injection caused drop of Tb after LPS administration}

Figure 4 illustrates the effect of pre-injection with AUDA on endotoxin fever in rats. Pre-injection with olive oil did not change the characteristic biphasic pattern of endotoxin fever, which corresponds with a previous report from our laboratory [38]. In this experimental group, fever started an hour after LPS injection and reached first peak $\left(38.09 \pm 0.12^{\circ} \mathrm{C}\right)$ after $2.5 \mathrm{~h}$. The maximum value of $\mathrm{Tb}$ during the second phase of fever $\left(38.52 \pm{ }^{\circ} \mathrm{C}\right)$ was observed 
Fig. 1 Changes of body temperature $\left({ }^{\circ} \mathrm{C}\right)$ over time $(\mathrm{h})$ of rats treated intraperitoneally at 8:00 with $500 \mu \mathrm{L}$ of olive oil (open squares, a) or with AUDA (b) in a dose of $5 \mathrm{mg} / \mathrm{kg}$ (closed squares), $15 \mathrm{mg} / \mathrm{kg}$ (open circles), or $30 \mathrm{mg} / \mathrm{kg}$ (open triangles). Closed circles represent normal circadian rhythm of body temperature in control rats. Sample size is indicated in parentheses. Black arrowheads represent the time of injection. Values are means \pm SEM at 30 -min averages. Asterisks indicate significant difference $(* * * p<0.001)$ between rats treated with AUDA in a dose of $30 \mathrm{mg} / \mathrm{kg}$ and non-treated animals

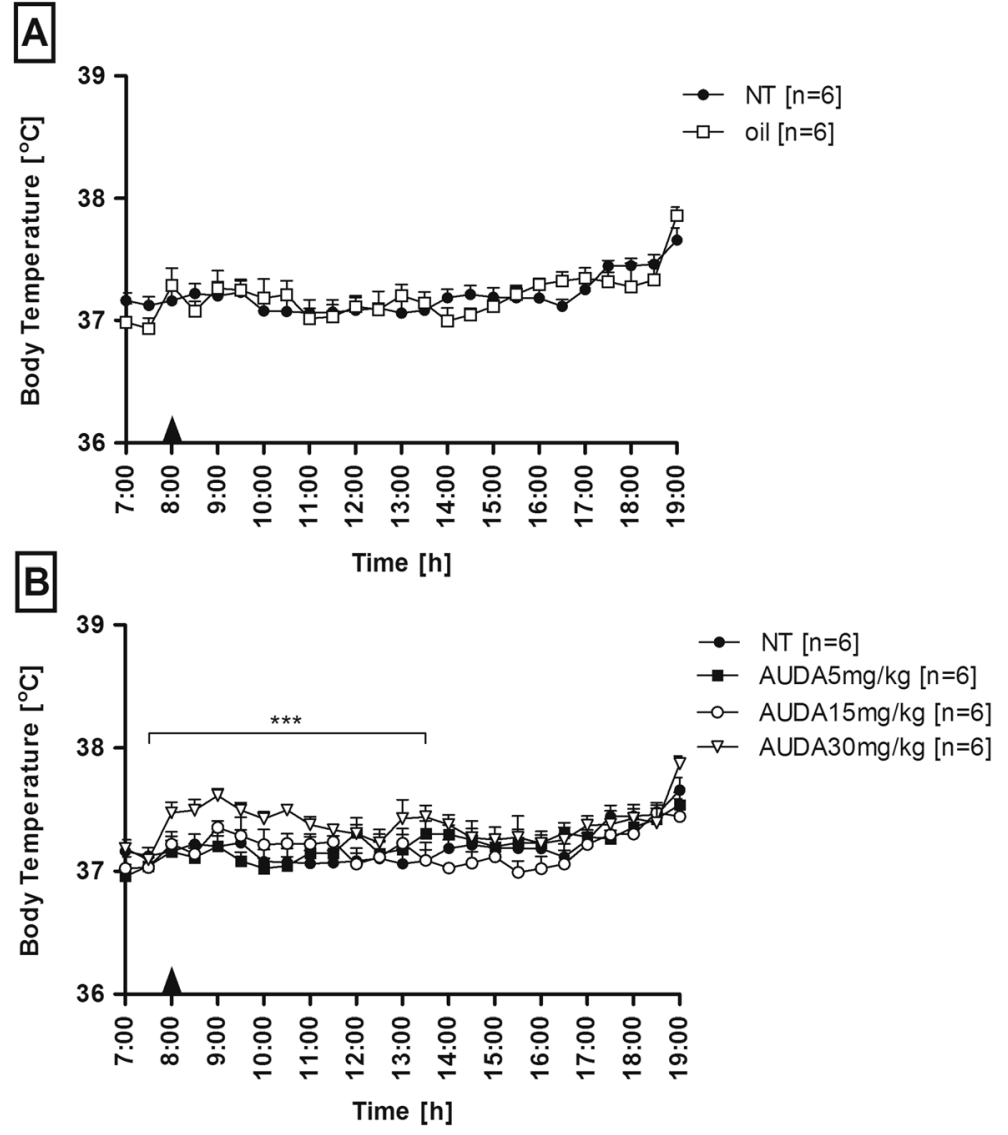

$6 \mathrm{~h}$ post-LPS injection. Then, a 4-h-lasting gradual decrease of Tb towards normal was observed. In contrary, the animals pre-injected with AUDA responded with a drop of $\mathrm{Tb}$ almost instantly after LPS administration to the minimum of $36.44 \pm 0.12{ }^{\circ} \mathrm{C}$. Then, temperature rose steadily. Whereas the first phase of endotoxin fever in this experimental group was completely diminished, the second phase with a $\mathrm{Tb}$ maximal value of $38.54 \pm 0.16{ }^{\circ} \mathrm{C}$ achieved an hour later was comparable to the "olive/LPS" group. However, for short time period (between 18:00 and 19:00), mean $\mathrm{Tb}$ in "AUDA/LPS" rats was significantly $(p<0.001)$ higher than in the olive/LPS group.

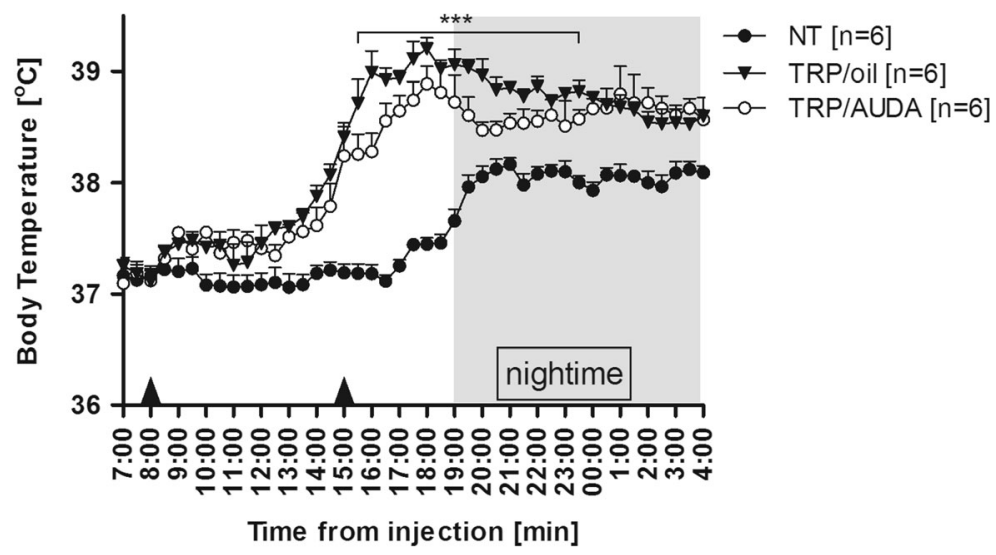

Fig. 2 Changes of body temperature $\left({ }^{\circ} \mathrm{C}\right)$ over time $(\mathrm{h})$ of rats treated s.c. at 8:00 with turpentine. Seven hours afterwards, animals received intraperitoneally AUDA in a dose of $15 \mathrm{mg} / \mathrm{kg}$ (open circles) or $500 \mu \mathrm{L}$ of olive oil (closed triangles) as a control. Closed circles represent normal circadian rhythm of body temperature in non-treated rats. Sample size is indicated in parentheses. Black arrowheads represent the time of injection. Values are means \pm SEM at 30-min averages. Asterisks indicate significant difference $(* * * p<0.001)$ between "TRP/oil" and "TRP/ AUDA" experimental groups 


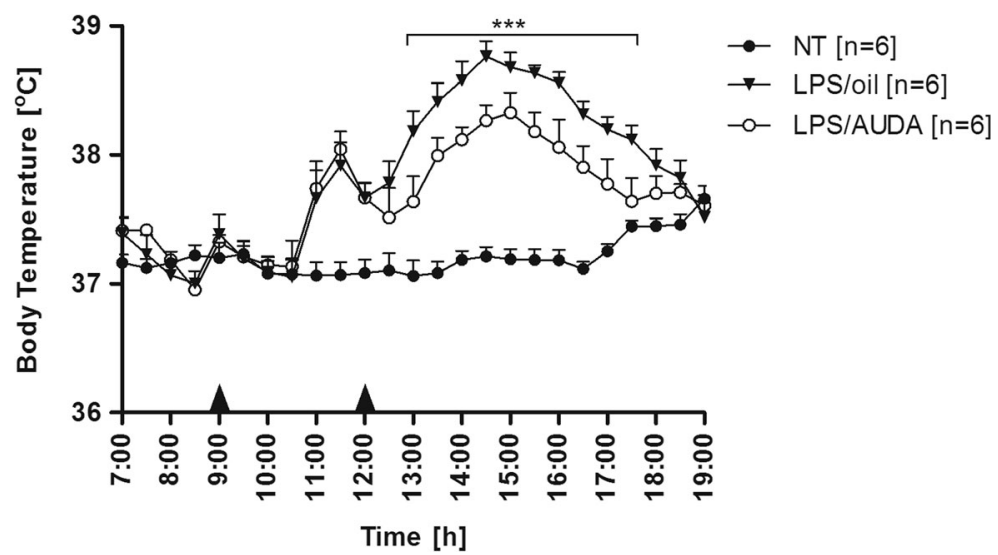

Fig. 3 Changes of body temperature $\left({ }^{\circ} \mathrm{C}\right)$ over time (h) of rats treated i.p. at 9:00 with LPS $(50 \mu \mathrm{g} / \mathrm{kg})$. Three hours afterwards, animals received intraperitoneally AUDA in a dose of $15 \mathrm{mg} / \mathrm{kg}$ (open circles) or $500 \mu \mathrm{L}$ of olive oil (closed triangles) as a control. Closed circles represent normal circadian rhythm of body temperature in non-treated rats. Sample size is

indicated in parentheses. Black arrowheads represent the time of injection. Values are means \pm SEM at 30-min averages. Asterisks indicate significant difference $(* * * p<0.001)$ between "LPS/oil" and "LPS/ AUDA" experimental groups

\section{AUDA did not affect the rise in plasma TNF- $\alpha$ after LPS injection in rats}

Plasma TNF- $\alpha$ concentration was measured an hour after LPS or saline injection to the rats pre-treated with AUDA or olive oil. This particular time point corresponds to the greatest decrease in Tb of AUDA/LPS rats as it was previously described. As can be seen in Fig. 5, in plasma of non-treated rats, as well as in the animals treated with saline an hour after olive oil or AUDA, TNF- $\alpha$ levels were below the detection range of ELISA kit used for experiments (the minimum detectable dose was $5 \mathrm{pg} / \mathrm{mL}$ ). In both groups of rats treated with LPS, we found a significant increase in TNF- $\alpha$ levels $(182 \pm 48 \mathrm{pg} / \mathrm{mL}$ in plasma of animals pre-treated with AUDA and $223 \pm 44 \mathrm{pg} / \mathrm{mL}$ in rats pre-treated with olive oil, respectively). However, the difference in TNF- $\alpha$ concentration between these two groups of animals was insignificant $(p>0.05)$.

\section{Injection of TNF- $\alpha$ antibodies did not affect the drop of Tb observed after LPS injection into animals pre-treated with AUDA}

To determine whether or not TNF- $\alpha$ is involved in the drop of Tb observed after LPS injection into animals pre-treated with AUDA, in separate experiments, rats were treated i.p. with TNF- $\alpha$ antibodies $1 \mathrm{~h}$ prior to the injection of SEH inhibitor or with $\operatorname{IgG}$ as a control. As can be seen in Fig. 6, subsequent injections with TNF- $\alpha$ antibodies, AUDA, and $\mathrm{NaCl}$ caused any noticeable changes in $\mathrm{Tb}$. Mean daytime $\mathrm{Tb}$ of rats from

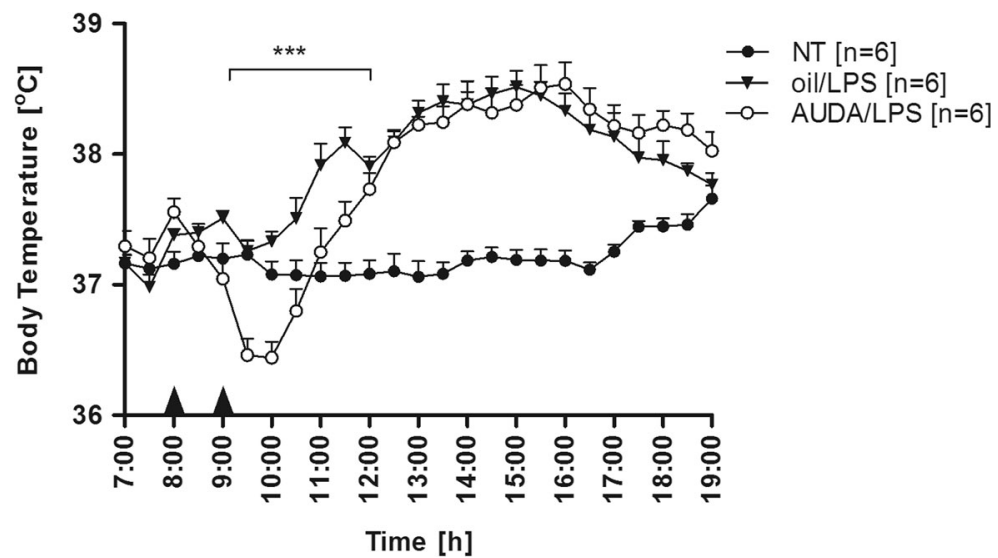

Fig. 4 Changes of body temperature $\left({ }^{\circ} \mathrm{C}\right)$ over time $(\mathrm{h})$ of rats treated intraperitoneally at 8:00 with AUDA in a dose of $15 \mathrm{mg} / \mathrm{kg}$ (open circles) or with $500 \mu \mathrm{L}$ of olive oil (closed triangles) an hour before LPS $(50 \mu \mathrm{g} /$ $\mathrm{kg}$ ) administration. Closed circles represent normal circadian rhythm of body temperature in non-treated rats. Sample size is indicated in parentheses. Black arrowheads represent the time of injection. Values are means \pm SEM at 30-min averages. Asterisks indicate significant difference $(* * * p 0.001)$ between "oil/LPS" and "AUDA/LPS" experimental groups 


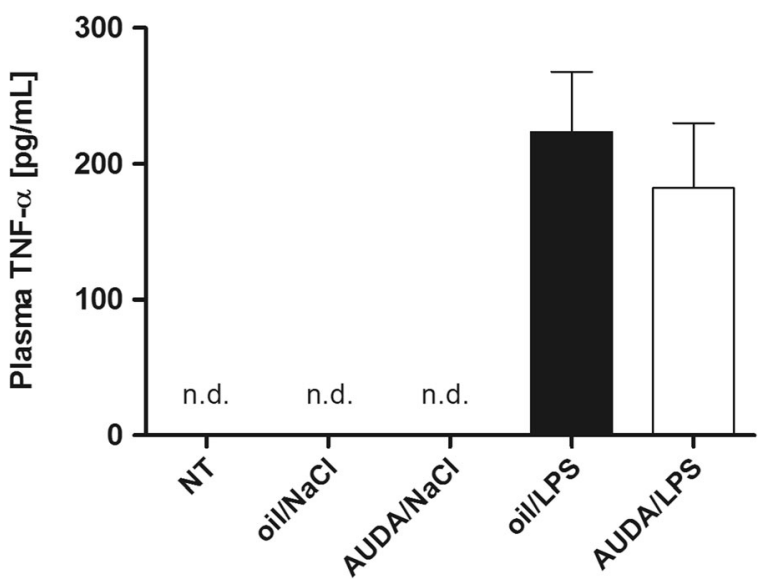

Fig. 5 Plasma TNF- $\alpha$ concentration (pg/mL) measured $1 \mathrm{~h}$ after LPS $(50 \mu \mathrm{g} / \mathrm{kg}$ i.p.) or saline $(1 \mathrm{~mL} / \mathrm{kg}$ i.p. $)$ injection to animals pre-treated intraperitoneally with AUDA ( $15 \mathrm{mg} / \mathrm{kg}$ ) or with $500 \mu \mathrm{L}$ of olive oil as a control. All groups correspond to those shown in previous experiment. Values are means \pm SEM calculated for plasma samples obtained from six animals for each experimental group

control group "TNFab/AUDA/NaCl" measured between 10:00 and 19:00 $\left(37.15 \pm 0.05^{\circ} \mathrm{C}\right)$ was comparable $(p>0.05)$ to non-treated animals $\left(37.21 \pm 0.07^{\circ} \mathrm{C}\right)$. It was also found that injection of TNF- $\alpha$ antibodies did not affect the drop of Tb observed after LPS administration to AUDAtreated animals. There were no significant $(p>0.05)$ changes in the course of febrile rise in $\mathrm{Tb}$ between rats from experimental groups "IgG/AUDA/LPS" and "TNFab/AUDA/LPS" within $4 \mathrm{~h}$ after LPS injection. In both mentioned groups of rats, characteristic pattern of endotoxin fever had changed from bi-phased to one-phased; however, in the animals treated with TNF- $\alpha$ antibodies, the peak period of febrile response was weakened in comparison to rats treated with $\mathrm{IgG}$. The mean $\mathrm{Tb}$ measured between 13:00 and 16:00 in the experimental group TNFab/AUDA/LPS $\left(38.23 \pm 0.07{ }^{\circ} \mathrm{C}\right)$ was significantly $(p<0.01)$ lower than in the $\mathrm{IgG} / \mathrm{AUDA} / \mathrm{LPS}$ control animals $\left(38.43 \pm 0.08{ }^{\circ} \mathrm{C}\right)$.

\section{Discussion}

Inhibition of sEH represents a novel therapeutic strategy to treat hypertension and inflammation and to reduce pain [28]. However, the usefulness of sEH inhibitors as anti-pyretic drugs has not been examined yet. The present study aimed to test whether $\mathrm{sEH}$ inhibition affects the normal $\mathrm{Tb}$ and $\mathrm{Tb}$ changes in the course of fever in rats. In the experiments, we used 12-(3-adamantan-1-yl-ureido)-dodecanoic acid (AUDA) - a urea-based potent sEH inhibitor most extensively described in the literature [for, e.g., see 5, 19,29]. We found that AUDA injected in a dose of $5 \mathrm{mg} / \mathrm{kg}$ as well as $15 \mathrm{mg} / \mathrm{kg}$ had no significant influence on $\mathrm{Tb}$ of rats (as can be seen in Fig. 1b), whereas $30 \mathrm{mg} / \mathrm{kg}$ induced meager but significant rise in $\mathrm{Tb}$ during early hours after injection. There are no experimental data that would clearly explain such result. To date, the testing in rodents and cell culture has found the ureabased sEH inhibitors to have extremely low toxicity and no adverse effects have been observed when treating rodents chronically [9]. However, to the best of our knowledge, $\mathrm{Tb}$ of animals treated with SEH inhibitors has never been measured and AUDA was never injected in such high intraperitoneal dose in animal studies. Since this compound does not directly affect phospholipase $A_{2}$, an enzyme that releases AA from membrane phospholipids [21] and without exogenous stimuli that induces liberation of AA, injection even a massive dose of sEH inhibitor should not lead to an increase in EET levels. Nevertheless, it was recently discovered that EETs constitute a substrate for COX leading to formation of corresponding epoxy-prostaglandins [24]. This should be

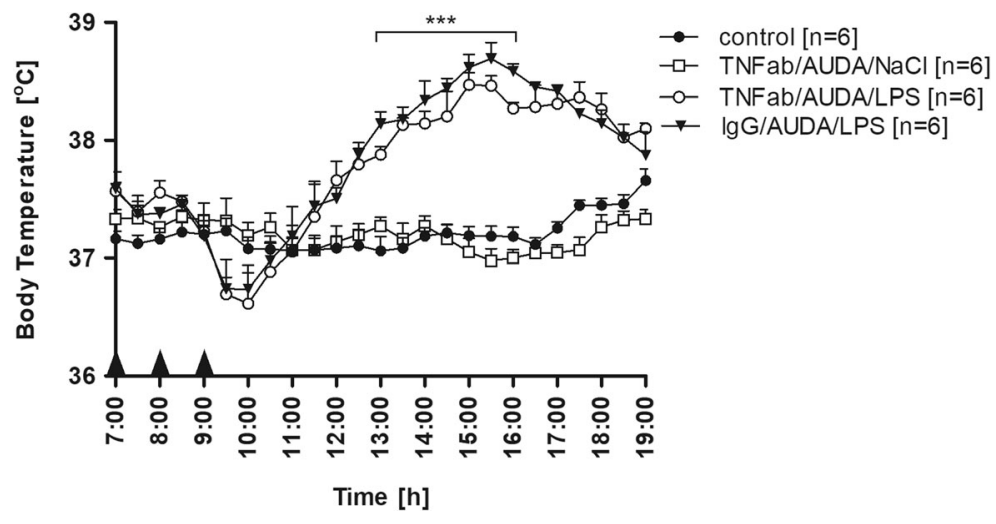

Fig. 6 Changes of body temperature $\left({ }^{\circ} \mathrm{C}\right)$ over time $(\mathrm{h})$ of rats treated intraperitoneally at 7:00 with TNF- $\alpha$ antibodies $(50 \mu \mathrm{g} /$ rat i.p.) and at 8:00 with AUDA in a dose of $15 \mathrm{mg} / \mathrm{kg}$ an hour before LPS $(50 \mu \mathrm{g} / \mathrm{kg}$ i.p.) (open circles) or $\mathrm{NaCl}$ (open squares) administration. Closed triangles represent $\mathrm{Tb}$ of rats treated at 7:00 with $\operatorname{IgG}(50 \mu \mathrm{g} / \mathrm{rat}$ i.p.) and at 8:00 with AUDA an hour before LPS injection (both in same concentration as above). Closed circles represent normal circadian rhythm of body temperature in non-treated rats. Sample size is indicated in parentheses. Black arrowheads represent the time of injection. Values are means \pm SEM at 30-min averages. Asterisks indicate significant difference $(* * * p<0.001)$ between experimental groups "TNFab/AUDA/ LPS" and "IgG/AUDA/LPS" 
considered especially when major pathway of EET metabolism (by sEH) is inhibited. Verification of the hypothesis that injection of high dose of sEH inhibitor leads to an increase in epoxy-prostaglandin level in the circulation and that it translates into an increase in $\mathrm{Tb}$ requires, however, separate studies. Therefore, in all the following experiments, we used AUDA in a dose of $15 \mathrm{mg} / \mathrm{kg}$. As we also established, this particular dose had no significant influence on hematological parameters in rats (data not shown).

To examine whether sEH inhibition affects fever, AUDA was given an hour before injection of LPS or turpentine as well as in the course of febrile response to these compounds. Not surprisingly, AUDA injected an hour before TRP had no influence on feverish changes in $\mathrm{Tb}$ (data not shown). Turpentine-induced fever is characterized with long (lasting at least 5-6 h) latency period, and as we presume, sEH inhibitor was biologically inactivated before it could affect endogenous components of fever mechanism. It is known that with the adamantine sensitive to P450 oxidation and the fatty acid chain sensitive to $\beta$-oxidation, AUDA is rapidly metabolized in vivo [21]. However, when inhibitor was administrated $7 \mathrm{~h}$ after turpentine injection, it significantly reduced the peak period of fever in rats (Fig. 2). A similar effect was observed when AUDA was injected $3 \mathrm{~h}$ after LPS, in experimental model of systemic inflammation (Fig. 3). These results provide the first experimental evidence that SEH inhibitor AUDA possesses anti-pyretic properties.

We believe that the reduction in fever caused by AUDA administration was the result of an increase in EET concentration that leads predominantly to pro-inflammatory cytokine downregulation and a decrease in the level of COX-2derived $\mathrm{PGE}_{2}$ (as illustrated in Fig. 7). This assumption is based on the earlier studies concerning the influence of this drug on mechanisms involved in the febrile response. Tao et al. showed that the LPS-induced elevation of sEH activities was significantly reduced in AUDA-treated mice. Moreover, in comparison with vehicle (LPS-treated group), administration of AUDA (10 mg/kg i.p.) markedly increased EET level and dampened the activation of nuclear factor (NF)- $\mathrm{KB}$ in LPS-challenged mice [34]. These findings are consistent with the previous reports indicating that EETs prevent amplification of inflammatory signaling pathways by inhibition of transcription factor NF-KB and IKB kinase [22]. Without NF-KB translocation to the nucleus, immune cells would not produce pro-inflammatory proteins, including TNF- $\alpha$, IL-6, and COX2 [27]. Furthermore, it was reported that AUDA enhances the anti-inflammatory effects in endothelial cells by increasing the EET-induced peroxisome proliferator-activated receptor gamma (PPARY) activity [20]. Activation of PPAR $\gamma$ negatively influences the production of inflammatory cytokines, such as TNF- $\alpha$, IL-6, and IL-1 $\beta$, by macrophages [7]. Rodent studies strongly support our assumption. In a murine model of renal ischemia reperfusion injury, pro-inflammatory cytokines
TNF- $\alpha$ and monocyte chemoattractant protein-1 (MCP-1) were significantly suppressed, while anti-inflammatory IL10 and transforming growth factor- $\beta$ (TGF- $\beta$ ) were enhanced by treatment with AUDA ( $10 \mathrm{mg} / \mathrm{kg}$ i.p.) as shown by realtime PCR. Furthermore, AUDA caused a decrease in plasma levels of another pro-inflammatory cytokine IL-6, while the concentrations of regulatory cytokines IL-4 and IL-10 were augmented [18]. Similarly, Schmelzer et al. showed that AUDA-butyl ester (AUDA-BE) metabolized in vivo to the AUDA decreased plasma levels of pro-inflammatory cytokines (IL-6 and TNF- $\alpha$ ) in mice injected with LPS [27]. Further work from this laboratory demonstrates also that when administered alone, AUDA-BE decreased the protein expression of COX-2 and was more effective in decreasing $\mathrm{PGE}_{2}$ levels in LPS-challenged mice than NSAIDs [26].

Interestingly, we found that AUDA injected an hour before LPS caused significant and rapid drop of $\mathrm{Tb}$ that almost completely diminished the first phase of fever (as can be seen in Fig. 4). Initially, we assumed that observed effect results from the TNF- $\alpha$ upregulation. TNF- $\alpha$ is the first cytokine that appears after LPS administration, peaks after $1-2 \mathrm{~h}$, and can exert both pyrogenic or anti-pyretic effects $[1,12,14]$. Surprisingly, we found no significant increase in plasma TNF- $\alpha$ concentration measured $1 \mathrm{~h}$ after LPS administration to animals pre-treated with AUDA compared to vehicle (Fig. 5). Furthermore, injection of TNF- $\alpha$ antibodies before AUDA did not protect against observed drop in $\mathrm{Tb}$ in LPS-challenged rats (Fig. 6), thus indicating that the discussed effect is TNF- $\alpha$-independent. Therefore, we assume that a drop in Tb after LPS injection into the animals pre-treated with AUDA might result from the sudden decrease in blood pressure (BP). It is generally accepted that LPS in high intraperitoneal doses (greater than $1 \mathrm{mg} / \mathrm{kg}$ ) provokes a decrease in blood pressure in rats [35], but still, little is known of the effect of low doses corresponding to those used in our experiments. Soszynski and Krajewska showed that LPS $(50 \mu \mathrm{g} / \mathrm{kg})$ injected i.p. into rats causes a significant increase in plasma level of potent vasodilator nitric oxide (NO) within $3 \mathrm{~h}$ [32]; however, some reports suggest that this effect does not have to translate into lowering blood pressure [25]. As we mentioned, recent findings showed that AUDA significantly elevates levels of vasorelaxing EETs in LPStreated mice [34]. In regard to interactions between EETs and NO, both appear to act independent; nevertheless, it was proved that EETs activate endothelial isoform of nitric oxide synthase (eNOS) [8]. In the light of these results, we presume that the observed drop in $\mathrm{Tb}$ is a consequence of a sudden increase in vasorelaxing agents as a consequence of synergizing effect of AUDA and LPS.

Inhibition of sEH is an emerging strategy for treatment of cardiovascular and inflammatory disorders. We showed that sEH inhibitors should also be considered as potential antipyretic drugs. Undoubtedly, non-steroidal anti-inflammatory drugs (NSAIDs) are one of the most widely prescribed 


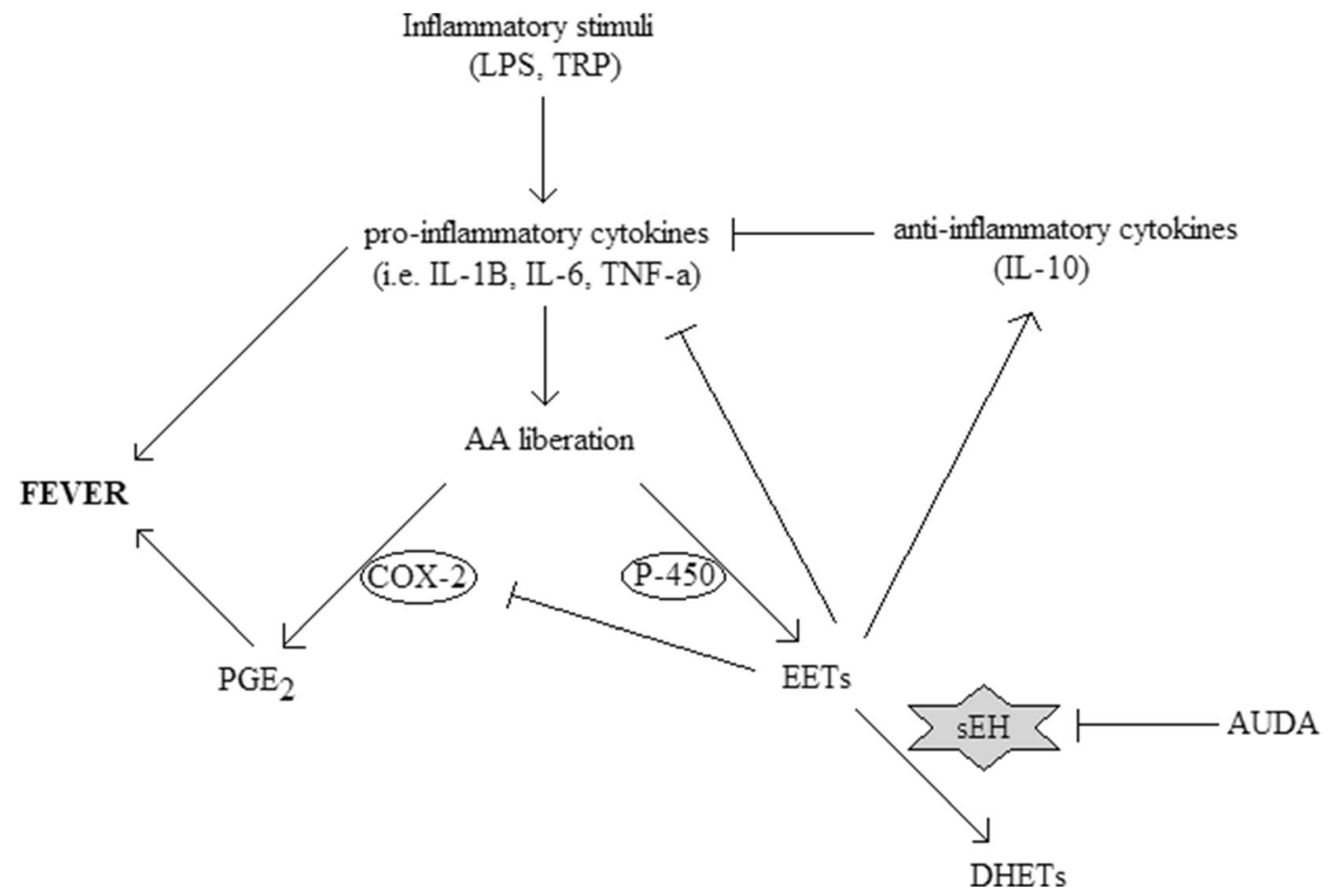

Fig. 7 Effects of EETs increased by sEH inhibition with AUDA on the main components of molecular mechanism of fever. On the diagram, $\downarrow$ arrowheads represent activation while $\perp$ inhibition. As a result of AUDA administration in the course of febrile response to inflammatory stimuli, DHET formation is inhibited and EETs produced from arachidonic acid

medications in the world for treating fever. The major problem with the use of these drugs is that their chronic administration is limited by the metabolic and cardiovascular side effects [30,33]. Moreover, NSAIDs are only marginally effective in lowering elevated $\mathrm{Tb}$ in specific clinical cases, i.e., in treating fever occurring after stroke that is often associated with poor outcomes [40]. We have previously proved in the animal model of cerebral hemorrhage that such rise in $\mathrm{Tb}$ is a PGE2-dependent response, however, it appeared to be not sensitive to a COX inhibitor, unlike the fever induced by LPS [37]. Drugs targeting sEH not only are safe in use, but also reduce the undesirable side effects and synergize well with NSAIDs and COX-2 blockers (COXIBs) [28]. They might be attractive in drug combinations allowing to reduce the dose of anti-pyretics used in clinics. Increased circulating levels of EETs caused by sEH inhibition reduce not only NF-KB nuclear translocation but also COX-2-dependent synthesis of $\mathrm{PGE}_{2}$ in both peripheral tissues and central nervous systems [36]. Furthermore, recent findings showed that sEH inhibitors could eliminate pain caused by the injection of the $\mathrm{PGE}_{2}$ that cannot be treated with either NSAIDs or steroids [11]. It clearly shows that sEH inhibitors by stabilizing EETs affect the biology of prostaglandins through several mechanisms that are not fully understood and involvement of receptors and signaling pathways cannot be ruled out as well [41]. Further studies should concentrate on investigating the by cytochrome P-450 monooxygenase are increased and available for a prolonged period. EETs acting by the mechanisms described in the discussion section lead to downregulation in fever mediators - cytokines and prostaglandins - thereby weakening fever

usefulness of newly discovered sEH inhibitors in combination with NSAIDs especially in clinical cases where topical therapy does not work.

\section{Conclusion}

The results of the present study clearly demonstrate that a potent sEH inhibitor AUDA injected in a course of endotoxin or aseptic fever significantly weakened the rise in $\mathrm{Tb}$ of rats. This effect of AUDA undoubtedly results from the increase in EET bioavailability that leads to an inhibition of NF-KB transcriptional activity and COX-2 enzymatic activity and in consequence to downregulation of fever mediators - cytokines and prostaglandins. Obtained results constitute the first experimental evidence that sEH inhibitors should be considered as potential anti-pyretic drugs and thereby should be further examined for their suitability in clinics. Since inhibitors of sEH synergize well with NSAIDs, combined therapy could allow to reduce the side effects resulting from chronic intake of NSAIDs or to increase the effectiveness of treatment, especially of patients who experience stroke. The present study provides also a new experimental model for studying the biological effects of newly synthesized sEH inhibitors and may as well contribute to the expansion of therapeutic area of interest for sEH inhibitors. 
Acknowledgements This study was supported by the Nicolaus Copernicus University Intramural Grant 2253-B to Jakub Piotrowski (Torun, Poland).

Compliance with ethical standards All procedures were approved by the Local Bioethical Committee for Animal Care (permission no. 9/2015).

Conflict of interest The authors declare that there is no conflict of interest.

Open Access This article is distributed under the terms of the Creative Commons Attribution 4.0 International License (http:// creativecommons.org/licenses/by/4.0/), which permits unrestricted use, distribution, and reproduction in any medium, provided you give appropriate credit to the original author(s) and the source, provide a link to the Creative Commons license, and indicate if changes were made.

\section{References}

1. Bastos-Pereira AL, Fraga D, Ott D, Simm B, Murgott J, Roth J, Zampronio AR (2014) Involvement of brain cytokines in zymosaninduced febrile response. J Appl Physiol 116:1220-1229

2. Blatteis CM, Li S, Li Z, Feleder C, Perlik V (2005) Cytokines, PGE2 and endotoxic fever: a re-assessment. Prostaglandins Lipid Mediat 76:1-18

3. Dennis EA, Norris PC (2015) Eicosanoid storm in infection and inflammation. Nat Rev Immunol 15:511-523

4. Dinarello CA, Cannon JG, Wolff SM, Bernheim HA, Beutler B, Cerami A, Figari IS, Palladino MA Jr, O'Connor JV (1986) Tumor necrosis factor (cachectin) is an endogenous pyrogen and induces production of interleukin 1. J Exp Med 163:1433-1450

5. Dorrance AM, Rupp N, Pollock DM, Newman JW, Hammock BD, Imig JD (2005) An epoxide hydrolase inhibitor, 12-(3-adamantan1-yl-ureido)dodecanoic acid (AUDA), reduces ischemic cerebral infarct size in stroke-prone spontaneously hypertensive rats. J Cardiovasc Pharmacol 46:842-848

6. Fang X, Kaduce TL, Weintraub NL, Harmon S, Teesch LM, Morisseau C, Thompson DA, Hammock BD, Spector AA (2001) Pathways of epoxyeicosatrienoic acid metabolism in endothelial cells. Implications for the vascular effects of soluble epoxide hydrolase inhibition. J Biol Chem 276:14867-14874

7. Feige JN, Gelman L, Michalik L, Desvergne B, Wahli W (2006) From molecular action to physiological outputs: peroxisome proliferator-activated receptors are nuclear receptors at the crossroads of key cellular functions. Prog Lipid Res 45:120-159

8. Hercule HC, Schunck WH, Gross V, Seringer J, Leung FP, Weldon SM, da Costa Goncalves AC, Huang Y, Luft FC, Gollasch M (2009) Interaction between P450 eicosanoids and nitric oxide in the control of arterial tone in mice. Arterioscler Thromb Vasc Biol 29:54-60

9. Imig JD (2006) Cardiovascular therapeutic aspects of soluble epoxide hydrolase inhibitors. Cardiovasc Drug Rev 24:169-188

10. Inceoglu B, Jinks SL, Ulu A, Hegedus CM, Georgi K, Schmelzer KR, Wagner K, Jones PD, Morisseau C, Hammock BD (2008) Soluble epoxide hydrolase and epoxyeicosatrienoic acids modulate two distinct analgesic pathways. Proc Natl Acad Sci U S A 105: 18901-18906

11. Inceoglu B, Wagner $\mathrm{K}$, Schebb NH, Morisseau C, Jinks SL, Ulu A, Hegedus C, Rose T, Brosnan R, Hammock BD (2011) Analgesia mediated by soluble epoxide hydrolase inhibitors is dependent on cAMP. Proc Natl Acad Sci U S A 108:5093-5097

12. Jedrzejewski T, Piotrowski J, Wrotek S, Kozak W (2014) Polysaccharide peptide induces a tumor necrosis factor- $\alpha$-dependent drop of body temperature in rats. J Therm Biol 44:1-4

13. Kim IH, Nishi K, Tsai HJ, Bradford T, Koda Y, Watanabe T, Morisseau C, Blanchfield J, Toth I, Hammock BD (2007) Design of bioavailable derivatives of 12-(3-adamantan-1-yl-ureido)dodecanoic acid, a potent inhibitor of the soluble epoxide hydrolase. Bioorg Med Chem 15:312-323

14. Klir JJ, McClellan JL, Kozak W, Szelényi Z, Wong GH, Kluger MJ (1995) Systemic but not central administration of tumor necrosis factor-alpha attenuates LPS-induced fever in rats. Am J Phys 268: 480-486

15. Kluger MJ (1991) Fever: role of pyrogens and cryogens. Physiol Rev 71:93-127

16. Kozak W, Kluger MJ, Soszynski D, Conn CA, Rudolph K, Leon LR, Zheng H (1998) IL-6 and IL-1 beta in fever. Studies using cytokine-deficient (knockout) mice. Ann N Y Acad Sci 856:33-47

17. Kozak W, Kluger MJ, Kozak A, Wachulec M, Dokladny K (2000) Role of cytochrome P-450 in endogenous antipyresis. Am J Phys 279:455-460

18. Lee JP, Yang SH, Lee HY, Kim B, Cho JY, Paik JH, Oh YJ, Kim DK, Lim CS, Kim YS (2012) Soluble epoxide hydrolase activity determines the severity of ischemia-reperfusion injury in kidney. PLoS One 7:e37075

19. Li J, Carroll MA, Chander PN, Falck JR, Sangras B, Stier CT (2008) Soluble epoxide hydrolase inhibitor, AUDA, prevents early salt-sensitive hypertension. Front Biosci 13:3480-3487

20. Liu Y, Zhang Y, Schmelzer K, Lee TS, Fang X, Zhu Y, Spector AA, Gill S, Morisseau C, Hammock BD, Shyy JY (2005) The antiinflammatory effect of laminar flow: the role of PPARgamma, epoxyeicosatrienoic acids, and soluble epoxide hydrolase. Proc Natl Acad Sci U S A 102:16747-16752

21. Morisseau C, Hammock BD (2013) Impact of soluble epoxide hydrolase and epoxyeicosanoids on human health. Annu Rev Pharmacol Toxicol 53:37-58

22. Node K, Huo Y, Ruan X, Yang B, Spiecker M, Ley K, Zeldin DC, Liao JK (1999) Anti-inflammatory properties of cytochrome P450 epoxygenase-derived eicosanoids. Science 285:1276-1279

23. Piotrowski J, Jedrzejewski T, Kozak W (2014) Heme oxygenase-1 induction by cobalt protoporphyrin enhances fever and inhibits pyrogenic tolerance to lipopolysaccharide. J Therm Biol 45:69-74

24. Rand AA, Barnych B, Morisseau C, Cajka T, Lee KSS, Panigrahy D, Hammock BD (2017) Cyclooxygenase-derived proangiogenic metabolites of epoxyeicosatrienoic acids. Proc Natl Acad Sci U S A 114:4370-4375

25. Sánchez-Lemus E, Benicky J, Pavel J, Larrayoz IM, Zhou J, Baliova M, Nishioku T, Saavedra JM (2009) Angiotensin II AT1 blockade reduces the lipopolysaccharide-induced innate immune response in rat spleen. Am J Physiol Regul Integr Comp Physiol 296:1376-1384

26. Schmelzer KR, Inceoglu B, Kubala L, Kim IH, Jinks SL, Eiserich JP, Hammock BD (2006) Enhancement of antinociception by coadministration of nonsteroidal anti-inflammatory drugs and soluble epoxide hydrolase inhibitors. Proc Natl Acad Sci U S A 103: 13646-13651

27. Schmelzer KR, Kubala L, Newman JW, Kim IH, Eiserich JP, Hammock BD (2005) Soluble epoxide hydrolase is a therapeutic target for acute inflammation. Proc Natl Acad Sci U S A 102: 9772-9777

28. Shen HC, Hammock BD (2012) Discovery of inhibitors of soluble epoxide hydrolase: a target with multiple potential therapeutic indications. J Med Chem 55:1789-1808

29. Simpkins AN, Rudic RD, Schreihofer DA, Roy S, Manhiani M, Tsai HJ, Hammock BD, Imig JD (2009) Soluble epoxide inhibition 
is protective against cerebral ischemia via vascular and neural protection. Am J Pathol 174:2086-2095

30. Sostres C, Gargallo CJ, Arroyo MT, Lanas A (2010) Adverse effects of non-steroidal anti-inflammatory drugs (NSAIDs, aspirin and coxibs) on upper gastrointestinal tract. Best Pract Res Clin Gastroenterol 24:121-132

31. Soszynski D, Krajewska M (2002) Lack of cross tolerance between pyrogenic effects of LPS and turpentine in rats. J Therm Biol 27: 229-237

32. Soszyński D, Krajewska M (2002) Time-course of changes in plasma nitric oxide following lipopolysaccharide and turpentine injection in rats. J Therm Biol 27:387-391

33. Süleyman H, Demircan B, Karagöz Y (2007) Anti-inflammatory and side effects of cyclooxygenase inhibitors. Pharmacol Rep 59: 247-258

34. Tao W, Li PS, Yang LQ, Ma YB (2016) Effects of a soluble epoxide hydrolase inhibitor on lipopolysaccharide-induced acute lung injury in mice. PLoS One 11:e0160359

35. Tunctan B, Sari AN, Kacan M, Unsal D, Buharalioglu CK, SahanFirat S, Korkmaz B, Falck JR, Malik KU (2013) NS-398 reverses hypotension in endotoxemic rats: contribution of eicosanoids, NO, and peroxynitrite. Prostaglandins Lipid Mediat 104-105:93-108

36. Wagner K, Inceoglu B, Gill SS, Hammock BD (2011) Epoxygenated fatty acids and soluble epoxide hydrolase inhibition: novel mediators of pain reduction. J Agric Food Chem 59:2816-2824

37. Walentynowicz K, Szefer M, Wojtal B, Terlecki P, Wrotek S, Kozak W (2006) Role of prostaglandins in heme-induced fever. J Physiol Pharmacol 57:73-82

38. Wrotek S, Jędrzejewski T, Nowakowska A, Kozak W (2015) Glutathione deficiency attenuates endotoxic fever in rats. Int J Hyperth 31:793-799

39. Wrotek S, Jedrzejewski T, Potera-Kram E, Kozak W (2011) Antipyretic activity of N-acetylcysteine. J Physiol Pharmacol 62: 669-675

40. Wrotek SE, Kozak WE, Hess DC, Fagan SC (2011) Treatment of fever after stroke: conflicting evidence. Pharmacotherapy 31:10851091

41. Yang C, Kwan YW, Au AL, Poon CC, Zhang Q, Chan SW, Lee SM, Leung GP (2010) 14,15-Epoxyeicosatrienoic acid induces vasorelaxation through the prostaglandin $\mathrm{EP}(2)$ receptors in rat mesenteric artery. Prostaglandins Lipid Mediat 93:44-51 